\title{
The spirit of the craftsman and the cultural consciousness of the Vocational Education
}

\author{
Liu ling 1,2 \\ Jinnan District, Tianjin, Tianjin, China, Jinnan District, Haihe Education Park, 85 million road. Tianjin \\ University School of Education
}

China; Zhejiang; 9 Xuefu Road, Yinzhou District, Ningbo (Ningbo College of Vocational

Technology)

Keywords: Vocational education; craftsmen spiritual culture; consciousness cultural practice

\begin{abstract}
Advocating the spirit of craftsmen has become the mainstream value and subject consciousness of our society. The practice of vocational education culture calls for the craftsman spirit. The reasons for the lack of cultural consciousness in vocational education are that the culture of vocational education lies in the state of being free, the lack of technological culture, and the mapping of social culture. In this regard, vocational education should take "the spirit of the craftsman" as the value basis of realizing the cultural consciousness of vocational education, shouldering the mission of cultivating and carrying forward the spirit of the craftsman, forming the cultural consciousness of the craftsman spirit, constructing the educating system of cultivating the craftsman spirit, formulating the system system that conforms to the spirit of the craftsman, and creating the spirit of the craftsman. The atmosphere of the environment.
\end{abstract}

\section{工匠精神与职业教育的文化自觉}

\author{
刘玲 1,2 \\ 1 天津大学教育学院, 津南区, 天津, 中国 \\ 2宁波城市职业技术学院，鄞州，宁波，浙江，中国
}

关键词: 职业教育;工匠精神文化; 自觉文化实践

中文摘要. 倡导工匠精神成为当前我国社会的主流价值和主体意识, 职业教育文化的实践呼唤 工匠精神。职业教育文化自觉缺失产生原因有职业教育的文化处在自在状态、技术文化的缺 乏、社会文化的映射等问题。对此, 职业教育应以 “工匠精神” 作为实现职业教育文化自觉 的价值基础, 肩负起培育和弘扬工匠精神的使命, 形成具有工匠精神的文化意识、建立培育 工匠精神的育人机制、制定符合工匠精神的制度体系、营造契合工匠精神的环境氛围。

\section{1. 引言}

在 2016年全国两会上,李克强总理在做政府工作报告中提出“培育精益求精的工匠精神”。 这是工匠精神首次出现在政府工作报告中。我国政府和社会與论对工匠精神的呼唤, 就是要 将其作为当下经济驱动的理念, 以应对技术危机和价值虚无两大全球难题。作为与经济社会 联系最为紧密的一种教育类型, 职业教育契合时代发展需求, 以高度的文化自觉, 以工匠精 神” 作为实现职业教育文化自觉的价值基础, 既是引导职业教育文化实践的现实需要, 也是丰 富职业教育文化的理论诉求。 


\section{2. 职业教育文化自觉的缺失}

作为文化组织，职业教育对文化自觉的要义旨趣的高度把握和深刻领会，是履行文化传 承创新职能的前提。“文化自觉是指生活在一定文化中人们对其文化有“自知之明”，明白它的 来历、形成过程, 所具有的特色和它发展的趋向, 不带任何“文化回归”的意思, 不是要“复古”, 同时也不主张 ‘全盘西化’或 ‘全盘他化’。自知之明是为了加强对文化转型的自主能力, 取得决 定适应新环境、新时代文化选择的自主地位。”[1]职业教育文化自觉, 主要指在文化上的觉悟 和觉醒, 理性把握文化的起源、形成、演变、特点和发展趋势, 进而牢牢把握文化根基和方 向, 发现和培育自身的内在优势源泉。正所谓: “传统文化在这里嬗变, 外来文化在这里同化, 社会主流文化在这里被超越”[2]。

\section{1 职业教育文化自觉的缺乏}

职业教育文化自觉的意识缺失的两种表现是, 一是受西方科学文化的片面影响, 技术文 化弱化; 二是忽视本国传统技术文化的作用, 传承创新乏力。因此, 我国当前倡导“工匠精神” 的目的，不是鼓励职业教育“文化回归”以及“全盘西化”，而是要求在学习借鉴日本德国等国 工匠文化，在教育的价值取向、内容方法上体现工匠精神的精神实质和当代价值。职业教育 文化自觉的内涵包含以下三个层次, 即文化的自知、自省和自新。结合工匠精神, 从以下三 个方面来分析职业教育文化自觉的缺失现状。

\section{1. 文化自知的缺乏}

这种自知包括在了解和熟悉自身文化的基础上，明了自身文化的来历、发展过程、特色， 并对自身文化及文化样式予以认同，也包括其他国家职业教育文化的了解和认识。主要包括 表现出来的形式之知、价值之知以及事实之知。形式之知就是通过技术文明表现出来的思维 方式和艺术形式，如，我国古代技术呈现的尚巧、精美，道技合一，“物勒工名”等。价值之 知指的是渗透在工艺作品中的价值。古代工匠精神以道德精神为中心, 与中国的伦理传统相 契合，“正德”、“利物”、“厚生”阐述了古代工匠精神的内涵和规约着古代职业教育过程的教 育原则，具体体现为：墨家的“强力而行”的敬业奉献精神、“切磋环磨”精益求精的精神、“兴 利除害”的爱国为民精神 [3]。事实之知，指的是各种工艺发展而产生的技能技巧的知识。今天 的中国主要是传承了传统文化的“形式之知”，而“价值之知”和“事实之知”则多数被抛弃了 ${ }^{[4]}$ 。 我国在追求“速度为王”的工业化进程中, 工匠精神渐渐丢失, 几乎丧之殆尽。而相比较德国、 日本、瑞士等国，工匠精神已经成为他国经济发展的制胜法宝。在此背景下，具有基础性、 战略性地位的我国职业教育, 不要妄自菲薄, 而需要全面系统地认知、深入发掘与传承创新 我国古代工匠精神，以“工匠精神”作为实现职业教育文化自觉的价值基础，将其进行现代诠 释, 应用到现实之中去。

\section{2.文化自省的缺乏}

文化自省是一种文化心态，一种途径，旨在唤醒人的文化自觉意识，促使人们深层次地 认识文化的发展规律，找到文化的发展方向，从而清醒地意识到文化的历史使命，并付诸实 践。从世界范围看，职业教育是大工业经济的产物，14 世纪以后，随着“行会制度”的衰弱和 大工业经济的诞生, 在广泛意义上（突破了行会限制）出现了专门培养劳力者劳动技能的教 育形态，并被纳入了国家教育制度 ${ }^{[5]}$ 。近代伊始，我国爱国开明人士倡导“教育救国”，认为 职业教育乃“救国要图”, 首要的是解决生计问题。主张通过解决生计问题, 最终实现“教育救 国”[6]。引进了西方工业成就之时, 职业教育也引进了科学主义的教育模式, 在教育层面导致 工作世界与生活世界的不统一，培育工业生产中“单向度的人”。面对全球技术危机的现代性 难题，德国的“工业 4.0”，美国的“制造业再造”纷纷出台之时，我国大力倡导“工匠精神”，作 为“中国制造 2025”、“优质制造”的精神驱动力。这也是对工业化社会效率主义至上、后工业 化社会的反思结果。如何让世界文明在职业教育作出具体化体现，发扬和创新“工匠精神”, 促进我国经济核心竞争力的提升，是职业教育必须做出的文化反思。 


\section{3.文化自新的缺乏}

文化自新指主要依靠自身的力量进行文化的创造和更新, 从而超越旧有文化。自主创新 体现出一种广阔高远的文化境界、发展的文化责任担当, 是最高层次的文化自觉。文化自新 需要“向内转”, 反求诸已, 发现和培育内在的文化优势。基于古代工匠精神, 我国创造了灿 烂的技术文明。可是, 低品质低价格的商品充斥如今的国内市场, 崛起的中产阶级在国外消 费仅 2015 年就达约 1.2 万亿元, 一场品质革命正在到来。往日的工匠, 就是如今的工人、工 程师、技术人员, 立足新时代, 需要激活他们作为创造主体的文化意识, 鼓励他们创造出表 里俱新、形质兼优、内涵丰厚的技术产品, 为时代立言, 为时代镌史, 成为民族的集体记忆 和时代的精神坐标。为呼唤工匠精神，中央电视台录制的《大国工匠》中八位匠人，以其技 术的原创力、思想的驭握力, 给人以心灵的震撼和道德提升。一定程度上, 职业教育的人才 培养难以满足经济社会的人才需求, 其文化自新的使命, 就是塑造和改造自身, 创造和培育 具有工匠精神的技术技能型人才。随着我国“一带一路”战略的深入实施, 职业教育要加快走 出去, 塑造国际化、开放型的职业教育, 和沿路各国的合作交流中创造更加先进的职业教育, 从而强化职业教育文化在转型中的自主能力和自主地位, 在世界职业教育之林独树一帜。

\section{2 职业教育文化自觉缺失的原因}

\section{1. 处在文化的自在状态}

从职业教育的文化现状看, 由于职业教育的发展历史较短, 文化建设仍处于自在自发的 状态，远没有达到自在自为的阶段。职业院校的定位是地方性、行业性、职业性，无论是以 制造业为主、还是服务业为主, 无论是综合性、还是行业性的职业院校, 尚未摆脱对普通教 育文化的模仿阶段, 文化现代价值及其育人功能体现不明显。为了推动职业院校明晰自身定 位, 注重特色文化建设, 教育部和各地教育部门进行职业院校校园文化品牌的评选, 促使部 分职业院校开始注重“职”的特点。如, 浙江建设职业技术学院的“鲁班文化”, 探索和实践鲁 班精神所蕴含的创新意识、质量意识、无私奉献精神、严谨求实精神 [7]。浙江纺织服装职业 技术学院的“红帮文化”，“红帮”在百年传承中，扮演着中国近现代服装业开拓进取的重要角 色, 积淀了“敢为人先、精于技艺、诚信重诺、勤奋敬业”的思想底蕴 ${ }^{[8]}$ 。此外，还有浙江工 商职业技术学院的“商帮文化”、浙江经济职业技术学院的“汽车文化”、浙江海运职业技术学 院的“海洋文化”、浙江艺术职业学院“尚美”文化等。但总体来说, 由于尚未摆脱普通教育的 影响, 职业教育对自身的独特定位和特色性把握不当, 还处在文化的自发自在状态, 尚成为 自觉自为状态。可以说, 工匠精神是打造具有本土特色的职教的文化因子, 由于缺乏对工匠 精神的价值认识, 工匠精神没有作为职业院校文化的灵魂, 更没有形成相应的培育机制和体 系。

\section{2. 技术文化的缺失}

技术文化广义的看是人类创造的一切技术物、技术知识，以及技术思想、技术规则规范、 关于技术的价值观等 ${ }^{[9]}$ 。工匠精神属于技术的观念文化, 传承工匠精神、技术文化是由职业 院校的历史传统和主体职责所决定的。工匠精神体现了技术文化的内涵, 是“生命基因”、“遗 传密码”, 契合职业教育的实践逻辑, 是人才培养目标的精神内核, 是学生的技术素养的人格 意义以及核心标志。但由于科学主义教育模式的影响，尚未形成技术特征、技术理想、技术 道德、技术人文素质的校园文化。在职业教育的课程、实践中, 往往注重讲述技术工艺的原 理与设备, 但容易忽略技术特征的历史沿革、技术与社会劳动、技术与环境等方面的学习要 求，导致技术文化育人的功能不足、技术创新能力不足。以至于忘记了技术产生的“初心”, 难以诗意地栖居在技术世界, 难以在技术思维、行为、态度上予以引导, 难以形成稳定的技 术文化能力。如, 浙江省评估院的数据显示, 高职院校的社会评价普遍不高, 即高职院校学 生第一年专业对口率普遍不高, 学生对专业的满意度、学生对学校的满意度不高。其重要原 因是技术文化的缺失导致学生技术精神和能力不足, 不能完全满足岗位需求。 


\section{3. 社会文化的映射}

学者刘晓认为, “工匠精神”是个时代的产物, 不是呼吁与刻意培养所能产生的。“价廉物 美”的消费观扼杀了“工匠精神”[10]。原因有二，一是我国处于追求消费产品低品质、低价格的 阶段。二是企业运行模式, 认为产品的质量完全系于机器设备, 不重视技术工人的素质, 认 为职校生的专业能力是完全不重视的, 只要听话、能吃苦耐劳就行 ${ }^{[1]}$ 。因此, 职业教育输送 的毕业生规格自然就对应上了企业的现实需求, 精益求精、追求品质的工匠精神就显得没有 市场。这与我国职业教育的人才培养目标有很大差距, 也与德国的双元制重视对学生技术素 养的培养大相径庭。当下在经济发展速度放缓形势的倒逼下, 在质量提升的强烈诉求下, 我 国社会对产品意识和人文素养予以高度关心。

\section{3. 工匠精神是实现职业教育文化自觉的价值基础}

在新的发展形势下, 工匠精神作为工业文明与世界文明的价值表征，作为对当代市场经 济发展“道德失范”现象的回应，被赋予了新的时代内涵。随着“中国制造 2025”国家战略的推 行、社会與论对工匠精神的呼唤, 工匠精神将成为全社会的主流价值和主体意识, 渗透到整 个产业系统、整个社会体系，甚至社会生活的方方面面。实践需要是职业教育文化发展的基 本动因, 工匠精神既体现了技术文化的内涵, 契合职业教育的实践逻辑, 也体现对受教育者 精神家园的关照。职业教育应自觉吸纳我国古代工匠精神的文化因子, 将古代工匠精神作为 实现职业教育文化自觉的价值基础，形成符合当下实际、具有时代内涵的工匠精神。

\section{1 “用心做事”的伦理精神}

我国社会出现了诚信缺失、职业精神落寞、敬业精神缺失、职业幸福感缺失，这是我国 社会伦理精神的颠覆, 精神的无家可归成为我国工业化进程中的一个普遍问题 ${ }^{[12]}$ 。人们普遍 地认为, 职业教育是解决“何以为生”的实践活动, “醉心于培训“有用的人”, 而非是解决“为 何而生”的教育思考乃至哲学问题, 是忽视人生存目的价值教育的, 是对“培育“有心的人’或“有 灵魂的人”之路的背道而驰, 认为在“工具理性”的膨胀下人的生存价值被压榨得荡然无存 ${ }^{[13]}$ 。 工匠精神是工业文明发展的最高精神成果的一种技术理性和价值理性相统一的具体化理解。 工匠们工作世界和生活世界统一，更让今天工业生产中的“单向度的人”可望而不可即，工匠 们的世界才是完整的人的世界，法天、法地、又天地合一[14]。“用心做事”的构建意义在于， 职业技术人才培养规格的高素质高技能, 集中体现在工匠精神的落实。工匠精神要求先修心 性再学技艺, 产生对内和对外的两种影响力。对内影响师生的价值选择、人格塑造、思维方 式、精神气质、道德情感、行为模式，达到中国古代“技进乎艺，艺进乎道”，道技合一的境 界, 以及最高境界——审美境界, 甘于寂寞、心无旁敬、精益求精, 形成道德修养和人格境 界。对外表现为学校的价值观和理想追求、精神风貌以及学校的个性和鬼力所在。

\section{2 “精益求精”的质量精神}

我国古代的工匠精神体现了对质量精益求精、对制造精雕细玩、对完美孜孜追求的精神 品质。标准、质量和品牌, 是各国在标准时代、质量时代、品牌时代经济的制胜法宝。质量 精神追求的是零缺陷或者追求很高的一种价值取向, 即把品质从 $99 \%$ 提高到 $99.99 \%$, 将产品 的每个细节尽可能做到极致，“对技能提升和品质追求死磕到底的精神”。我国质检总局提出 质量包括四种: 产品质量、服务质量、工程质量、环境质量。2 016 年 4 月、 8 月国务院常务 会先后决定实施《装备制造业标准化和质量提升规划》, 以及消费品标准。两次会议旨在以 先进标准引领消费品质量提升和装备制造业升级 ${ }^{[15]}$ 。2016 年 9 月 10 日, 浙江省率先颁布《浙 江省标准强省质量强省品牌强省建设“十三五”规划》，成为践行从中国制造到中国创造、从 中国速度到中国质量、从中国产品到中国品牌“三个转变”的示范省, 率先迈入标准时代、质 量时代、品牌时代。在这个背景下, 追求卓越、崇尚质量将成为全社会的价值导向和时代精 
神。职业教育应以标准、质量、品牌作为发展的核心理念和价值取向。职业教育的人才培养 能力、技术服务和技术研发的能力, 就是要求专注于标准、质量、品牌, 不凑合、不马虎, 杜绝“差不多”、“凑合”现象，任何行为必须有章可循，杜绝一切随意。

\section{3 “融会贯通”的实践精神}

“心传体知”是中国古代工匠精神的价值实现，古代工匠具有“体知躬行”的学习过程 ${ }^{[16]}$ 。 世界教育创新峰会(WISE)与北京师范大学中国教育创新研究院于 2016 年 6 月 3 日共同发布 《面向未来: 21 世纪核心素养教育的全球经验》研究报告显示, 最受各经济体和国际组织重 视的七大素养分别是：沟通与合作、创造性与问题解决、信息素养、自我认识与自我调控、 批判性思维、学会学习与终身学习以及公民责任与社会参与。核心素养教育体现了国际教育 改革的发展动向，是对国际教育改革已有经验的发展和超越。在新的环境下，全球许多经济 体和国际组织都在思考应如何培养未来公民，以使其能够更好地适应 21 世纪的工作与生活。 基于对未来公民形象的追问，他们提出了 21 世纪素养等理念。未来 30-50 年，能源、信息、 环境、人口健康、重大工程等对材料和制造的需求将持续增长, 先进材料和制造的全球化、 绿色化、智能化将加速发展, 制造过程的清洁、高效、环境友好日益成为世界各国追求的主 要目标。现代化工业体现出集成化、自动化和连续化的特征, 为适应智能化工业时代的到来, 尤其需要通过实践环节中学会知识迁移, 掌握操作技法和实践技艺。为此, 职业教育的人才 培养要通过对知识、技术、技能的学习、研究、思考, 了解完整产业链的知识、技术、技能, 了解产品的改革和产业发展方向, 感受形成工艺的历史文化, 从中体会工艺的价值与工匠的 地位 ${ }^{[17]}$ 。

\section{4 “利物厚生”的爱国精神}

工匠群体就是一个共同体，共同体所拥有的精神实质是伦理精神和道德精神的统一，把 个人至善与社会至善有机融合起来。我国的现实坐标正处在“拉美陷阱”、“修昔底德陷阱”、“塔 西佗陷阱”, 期待实现更高水平跃迁的阶段。瑞士、德国、日本等国, 在很大程度上, 归功于 工匠精神对民族经济的崛起和发展的巨大支撑作用和精神动力。匠心筑“梦”，凭的是“利物厚 生”的精神, 靠的是传承和钻研、专注与磨砺。“利物”是指掌握创造物质财富的生产活动, “厚 生”则指工匠的劳动要服务于治国和惠民，与“经世致用”统一而不可分。我国产品的质量水平 和竞争力, 关系到中国水平、优质制造, 关系到民族经济的发展, 中国制造强国的梦想以及 中国梦的实现。因此, 充分地系统地吸收消化学习德国、日本等国的匠人文化、手工业文化, 融合发展, 形成具有中国特色和世界水平的职业教育。“道胜于器, 道高于器”, 中国当代工 匠要适应人类社会要求和本民族自身的新发展, 为实现中国制造强国的中国梦、提高现代化 水平而努力。

\section{4. 职业教育文化自觉呼唤工匠精神的培育}

工匠精神作为职业教育文化的核心和灵魂, 以“立德树人”为根本，融入现代职业教育体 系建设中, 形成具有工匠精神的文化意识、育人机制、制度体系、與论环境, 是文化实践的 自觉使命。

\section{1 形成具有工匠精神的文化意识}

文化意识是现代人文化素质的核心层次，也是人们产生行为的理性基础或精神动力，主 要表现为人们持有的世界观、价值观、理想情操、道德观念、思维方式 ${ }^{[18]}$ 。美国当代教育家 乔治·泰勒认为, 个人的哲学信念是认清自己生活方向的唯一有效的手段。工匠精神是文化传 统与文化精神的理性抽象和认同, 浸透和附着在各种文化载体及行为主体上, 是一种软技能, 体现为“卓越”、“绿色”、“精益求精”、“尚美”、“劳动尊严”、“人的尊严”等理念。在倡导技术 进步、生产方式变革的时代大背景下, 工匠精神要演化为代表职业院校整体精神追求的主体 
精神, 成为居于职业院校最高层次的主体文化, 并凝聚成沁人心脾的, 具有强大感召力、凝 聚力、渗透力的文化主旋律。在具体实践中, 要将工匠精神融入职业院校人才培养的全过程 中去, 让师生共同接受并加以自觉传承和弘扬, 成为师生思维和行为的“文化基因”、“文化模 式”，成为职业院校文化的核心标志、“文化名片”。职业院校师生应牢固树立具有工匠精神的 文化意识, 进而养成良好的工匠习惯，贯彻到一生的事业之中。

\section{2 建立培育工匠精神的育人机制}

国务院办公厅印发的《关于深化产教融合的若干意见》要求“强化企业重要主体作用”。 为更好地培养具有工匠精神的技术技能人才，应建立“校企交替、共育工匠”的技术技能人才 育人机制, 变“机械更替式”为“灵活交替式”的人才培养方式 ${ }^{[19]}$ 。围绕工匠精神, 在积极完善 人才培养模式的同时, 不断借鉴吸收先进的教育理念和现代教学管理制度, 在教学目标、教学 内容、教学方式、质量评价和教学资源整合方面进行系统改革, 建立以工匠精神为核心的育 人机制。同时, 建立起联系协调机制、互相制约机制等。如, 2016 年 6 月人力资源和社会保 障部办公厅关于印发《技工院校工匠精神教育课教学大纲（试行）》，要求并指导技工院校 根据教学大纲要求安排教学。2016 年秋季学期, 面向全体在校生将工匠精神教育作为开学第 一课主要学习内容。从 2017 年起, 工匠精神教育课作为新生入学第一学期的德育必修课程, 纳入各专业教学计划, 利用学习高技能人才楷模专题教育模块、入学教育等学时, 安排教学 一般 10 课时左右。编印《工匠精神读本》, 纳入教学体系, 进行考核评价。

\section{3 制定符合工匠精神的制度体系}

工匠精神不是道德与情操的伴随物, 而是社会集体约束、身份认同的社会化产物。行业 协会学会的知识引导、标准建立、工程师资格认证、教育培训等一系列活动, 是“工匠精神” 长盛不衰的重要因素 ${ }^{200}$ 。与此同时, 全球标准、合规高效, 是体现工匠精神的行为准则和价 值观念。职业教育要以开放的姿态, 融入到全球规则体系之中, 推动构建契合工匠精神的制 度体系。现实层面, 为了培育工匠精神更具可操作性和可推广性, 必须建立与工匠精神相配 套的科学的制度化管理体系, 如现代学徒制度、招生考试制度、校企合作制度、质量评价制 度、财政拨款制度等, 促进职业教育育人的整体优化。如, 2016 年 6 月, 中国科协代表中国 正式加入 《华盛顿协议》, 它所对应的是本科层面的工程教育。中国加入针对“工程技术专家” 认证的《悉尼协议》势在必行, 对中国高职院校层面提升工程教育水平、提高专业工程师培 养质量具有重要意义。

\section{4 营造契合工匠精神的环境氛围}

朱歇尔·波兰尼说, 我们的信仰是以我们所处的文化环境为条件的。第三次全国职业教育 工作会议上指出, 要树立正确人才观, 培育和践行社会主义核心价值观, 着力提高人才培养 质量, 弘扬“劳动光荣、技能宝贵、创造伟大”的时代风尚, 促进形成“崇尚一技之长、不唯学 历凭能力”的社会氛围[21]。“工匠精神”正是这个时代风尚的缩影。按照职业院校的办学理念和 理想追求, 营造和改善环境, 突出“工匠精神”特点, 使职业院校文化的具体形态融进更多的 技术道德、技术理想、技术特征、技术素养。如，宁波城市职业技术学院艺术分院探索以“视 觉东方” 为理念的人才培育模式, 以东方传统美学为核心, 成立了漆器、首饰、布衣、陶艺等 二十余个工作坊, 培育学生的工匠精神, 加强学生的职业素养和人文精神教育。组织开展“千 名工匠进校园” 活动, 宣传技术工人的职业精神, 使学生受到精神感染和情感激励。此外, 营 造校企合作、社会崇尚“工匠精神”的良好氛围。

综上所述, 将工匠精神融入文化建设是新形势下职业教育的文化自觉。职业教育要利用 好良好传统和现有的社会基础, 培育和弘扬“工匠精神”, 从盲目自在的状态转变为自觉自为 状态，主动地对文化传统进行系统地批判、重构和创新。以“工匠精神”引领技术技能人才培 育, 用“慢”的精神陶铸职业信念, 用“专”的信念提升职业能力, 用“创”的理念助推职业发展, 


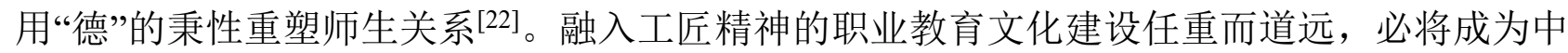
国特色社会主义先进文化的组成部分，以实现文化强国的目标。

\section{致谢}

基金项目：2016 年国家教育科学基金“十三五”规划项目《现代职业教育的工匠精神研 究》批准号 BJA160057

\section{References}

[1] Fei Xiaotong. Reflection Dialogue Cultural Consciousness,[J]. Journal of Peking University (Social Sciences Edition),1997(3): 22.

[2] Shen Wei. On the Five Basic Principles of Cultivating College Cultural Brand under the New Situation[J].Research on ideological and political education, 2013(10):75.

[3] Xue Dong. On the Value Implication of Ancient Craftsmanship, Vocational and Technical Education Forum, [J].2013(34):94-96.

[4] Chi Yun, Chai Yan. Self-consciousness, Self-confidence and Self-enhancement - Internal Drive to Maintain the Culture of Contemporary China[M]. Publishing House of Jinan, 2013.01, p7.

[5] Xu Pingli. Historical Logic and Philosophical Foundation of Vocational Education [M]. Guangxi: Guangxi Normal University Press, 2010(6):131.

[6] Liu Ling. Values of Vocational Education: Connotation, Structure and Function [J]. Vocational Education Forum, 2016. (12) : 15.

[7] Xu Gongfang, Li Qiang, Deng Wenhua. Carrying Forward Lu Ban Spirit and Cultivating High-qualified Architects [J]. Research in Higher Education of Engineering,2010(06):103.

[8] Wang Guohai, Shen Chaohui. Inherit the Essence of Hongbang Culture to Create Campus Cultural Brands [N].China Education Daily, 12 of January,2012, the third edition.

[9] Cheng Yikang. Technical Culture-Cultural Education of Technological Practical Talents [J].Vocational and Technical Education Forum, 2016 (24):14.

[10]Liu Xiao. "a craftsmanship Spirit of Striving for the Best " is a by-product [J]. Communication of Vocational ,2016 (16):77.

[11]Xue Guoqing. Understanding a craftsmanship Spirit of Striving for the Best [J]. Vocational and Technical Education Forum, 2016(24), P1.

[12] Song Jing. Study on Ethics of Modern Vocational Education [D], Tian Jin: Tian Jin University, $2013(6): 1-2$.

[13] Wu Yalin.Values and Education[M]. Beijing: Beijing Normal University Press, 2009:7-9.

[14]Tang Linwei. Romantic "Artisan Spirit" [J]. Vocational and Technical Education Forum, 2016(17):1.

[15]Li Keqiang presides over the executive meeting of the State Council [N].24,August,2016.

[16]http://finance.sina.com.cn/roll/2016-08-25/doc-ifxvitex8952304.shtml.

[17]Kong Baogen. Practice Ways of Cultivating "Artisan Spirit" in Higher Vocational Colleges [J]. Journal of Ningbo University, 2016 (5):54.

[18]Yan Yifan. University's Mission and Responsibility [M].Beijing: Educational Science 
Publishing House, 2007: 83.

[19]Zhuang Xizhen. Artisan Spirit from Multidimensional Perspective: Analysis and Interpretation of Connotation [J]. China Higher Education Research， 2017(5):96.

[20]Wang Xiaoming and Lin Xueping. Explore the Origin of Artisan Spirit [N].Economic Daily, 28,July,2016,the $14^{\text {th }}$ edition.

[21]Wu Jing, Liu Yizhan. Carrying Forward the Spirit in glorious skills of Labor and Precious Creation and Make Great Era of Fashion[N].Guangming Daily,24,June,2014 ,the first edition.

[22]Zhuang Xizhen. Leading high-skilled Talents Cultivation with "Artisan Spirit" [J].China Education Daily, 21,August,2017, the third edition. 